\title{
Constructing social futures for climate-change impacts and response studies: building qualitative and quantitative scenarios with the participation of stakeholders
}

\author{
Simon Shackley ${ }^{1, *}$, Robert Deanwood $^{2, * *}$ \\ ${ }^{1}$ Tyndall Centre for Climate Change Research, Manchester School of Management, UMIST, Manchester M60 1QD, \\ United Kingdom \\ ${ }^{2}$ Department of Planning and Landscape, University of Manchester, Oxford Road, Manchester M13 9PL, United Kingdom \\ ${ }^{* *}$ Present address: Entec UK Ltd, Gables House, Kenilworth Road, Leamington Spa, Warwickshire CV32 6SX, United Kingdom
}

\begin{abstract}
This paper describes the development of socio-economic scenarios, in both qualitative and quantitative terms, for use in integrated assessment modelling of the impacts of climate change in 2 contrasting English regions: East Anglia and the North West. The need for socio-economic scenarios is discussed, and the 'mediating' role that they play between intellectual debate and policy deliberation is analysed. Four scenarios are constructed for each region: regional enterprise, global sustainability, regional stewardship and global markets, and we provide the rationale for the socioeconomic and policy changes we propose under each scenario. Spatial mapping of 2 of the scenarios in each region is then conducted for 3 illustrative issues (built development, biodiversity and coastal zone), and a sample of non-spatial agricultural variables is inferred. A major focus of the paper is an examination of the experience of engaging stakeholders in the development of the socio-economic scenarios. We explore, in particular, how stakeholders reconciled a given long-term scenario framework with their shorter-term and particular policy-driven requirements.
\end{abstract}

KEY WORDS: Socio-economic scenarios $\cdot$ Regional climate-change impacts $\cdot$ Stakeholders

Resale or republication not permitted without written consent of the publisher

\section{INTRODUCTION}

Climate change induced by greenhouse gas emissions occurs on decadal time scales, over which time societies and economies will also change. Climatechange impacts and adaptation will occur not in today's, but in a future world. 'Scenarios', which are self-consistent, credible storylines of how socio-economic systems may develop in the future, can be used to provide the socio-economic backdrop for climatechange studies. In this paper, we report on the development of socio-economic scenarios (SES) for use in a UK-government-comissioned, model-based integrated assessment of the impacts of climate change upon hydrology, biodiversity, agriculture and the coastal zone in 2 contrasting English regions: East Anglia and the North West (the REGIS project). We do not present here the actual results of the integrated assessment: these are presented elsewhere (www.ukcip.org.uk/ integ_assess/integ_assess.html). The need for socioeconomic scenarios for each of the 4 above domains in the REGIS project emerges because of the role of socio-economic change and policy decisions in understanding the future state of those domains. For example:

- The vulnerability of the coastal zone to climate change depends upon the standard of protection provided and the extent of coastal developmentdecisions which are socio-economic and related to policy and politics. 
- Crop selection and cultivation practice depends upon many other variables apart from climate, including crop yields, crop prices, costs of other inputs, subsidy policies, other environmental restrictions, and so on. Such variables are the result of economic transactions and socio-political decisions.

- The vulnerability of biodiversity to climate change is likely to be influenced by the way in which sites, habitats and species are managed. Such decisions are partly social, for example, dependent upon available resources. How society in the future will perceive and value biodiversity will have an important influence on resources and biodiversity management.

The SESs had to provide 2 distinct types of inputs to the integrated assessment. Firstly, some quantitative inputs to numerical models of land use, the coastal zone and hydrology were required from the SESs for those variables which are dependent upon future socio-economic change and policy decisions. Secondly, SESs provided the context for interpreting the results of numerical modelling, as was the case for the biodiversity domain within REGIS.

There is now a considerable literature on scenarios for use in environmental assessment and policy development, and a correspondingly vigorous debate in academia and policy circles concerning their applications (e.g. van der Heijden 1996, Ringland 1998, DTI 1999, Yohe et al. 1999, Lorenzoni et al. 2000a,b, IPCC 2001, Strzepek et al. 2001, UK Climate Impacts Programme 2001, VISIONS 2001, Berkhout et al. 2002). In this paper we wish to contribute to this debate through addressing the following questions:

- How can stakeholder communities be included in the scenario-building process in a way that encourages maximal engagement of the stakeholders with the outputs of research and analysis?

- How can we quantify SESs which are derived from a qualitative development of different storylines and what problems are implied by a quantification?

\subsection{Why do we need SESs?}

The traditional 'predict and provide' approach to foresight and forecasting has a distinct benefit over scenarios, which is also its weakness: it provides a single prediction of the future. The benefit of predictive forecasting is that it reduces the uncertainty facing decision-makers. In reality, that may be an illusory benefit, however, because the prediction is most often incorrect (Ascher 1981), resulting in sometimes costly mistakes and bad decisions (e.g. Collingridge 1992, IAPA 1998). The demand for reduction in uncertainty is best seen as a political and institutional pressure, which arises from the dominant forms of policy legitimation through recourse to scientific knowledge in industrialised societies, as analysed by Ezrahi (1990). This politico-institutional pressure for certainty is somewhat at odds with the pressure from the scientific community itself to fully acknowledge and explore the properties of uncertainty.

Scenarios help to open-up to scrutiny by policymakers and stakeholders the uncertainty of the decision-making context, yet they limit exploration of uncertainty to a discrete number of possibilities, only a small number (usually 2 to 4 in past practice) being considered. Scenarios provide what we can term 'constrained uncertainty'. Pragmatic considerations favour constrained uncertainty, namely the organisational and cognitive barriers to utilising a large number of different scenarios, especially where there are no simple quantitative indicators for comparison, and where multiple agents are engaged in the policy-development process (though there are a few instances where larger numbers have been employed in policy deliberation, e.g. Lempert 2000, IPCC 2001). Wider stakeholder participation has become an important objective of policy processes in many countries, and this also helps to explain why new approaches to accommodating diverse perspectives and potentially radically different futures have become more salient. A discrete number of suitably differentiated scenarios can permit diversity whilst allowing the policy process and its assessment functions and negotiations to be manageable.

\subsection{Independent versus co-evolutionary SESs}

Climate-change scenarios are well established, and 4 scenarios (high, medium-high, medium-low and low) have become embedded in climate-change impacts research in the UK through the agency of the government's UK Climate Impacts Programme (UKCIP) (Hulme \& Jenkins 1998, McKenzie-Hedger et al. 2000). The UKCIP then commissioned development of SESs, and 4 such scenarios were developed by Berkhout et al. (2001) from a framework derived from international research performed on behalf of the Intergovernmental Panel on Climate Change (IPCC) (UKCIP 2001, Berkhout et al. 2002) (see Fig. 1).

There are 2 ways of combining climate change with SESs (see Fig. 2). One is to treat both sets of scenarios as formally independent (Fig. 2, left). The SESs do not take any account of climate change, and both scenario sets provide separate inputs to the system models which are run at the desired future time point (2050, 2080 , etc.). The second approach is to allow for interaction between climate change and socio-economic 


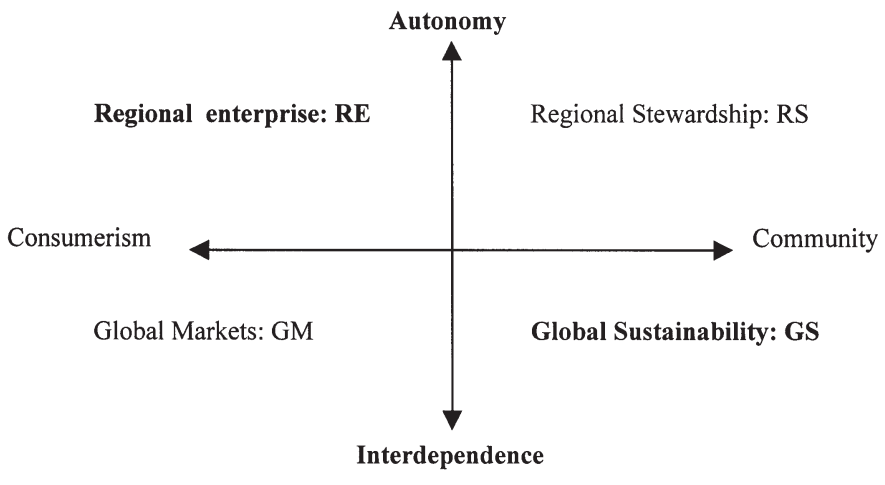

Fig. 1. The socio-economic scenario (SES) framework (adapted from Berkhout et al. 2000, 2001, UK Climate Impacts Programme 2001, after IPCC 2001)

changes prior to the integrated model run, an approach which has been termed co-evolutionary (Lorenzoni et al. 2000a) (Fig. 2, right). If vulnerable systems such as water resources are seriously affected by climatic factors, including (inter alia) climate change, then this will influence the social and political response to the protection of those systems not just in the 2050s or 2080s, but probably much sooner. These particular responses will clearly have a impact upon the subsequent vulnerability of such systems to climate change in 50 to $80 \mathrm{yr}$ time. Indeed, coastal protection policy is already partly driven by the perceived direct effects of climate change, with the height of new seawall defences in the UK being raised by $4 \mathrm{~mm} \mathrm{yr}^{-1}$ in response to climate model simulations (MAFF 1999). Co-evolutionary scenarios are clearly more realistic of social systems, which are responsive and will change because of the understanding and/or experience of climate change and its impacts. Non-climate-change SESs are, nevertheless, useful for at least the following 4 reasons.

- Firstly, they are conceptually more straightforward than fully interactive socio-economic and climatechange scenarios. This is an important consideration when working with a wide range of stakeholders, many of whom are not at all familiar with a scenariobased approach to analysis. Interactive scenarios amplify what is already a high degree of complexity and uncertainty. Such complexity and uncertainty may be justified intellectually, yet it may significantly hinder the likelihood of effective stakeholder engagement.

- By definition, 'non-climate-change' SESs provide the extreme case of a society that does not respond at all to the threat of climate change over the next 50 to 80 yr. For example, if the SES which maximises stress upon biodiversity, water, coastlines and agricultural systems is combined with a high level of climate change, we are likely to have something approaching the 'worst-case' scenario. Knowledge of potential extremes is helpful in devising robust policies.

- Such independent scenarios permit a clearer distinction to be drawn between the effects of physical climate change and socio-economic changes (and hence their use clarifies the precise effect of responses at a given point in time; Klein \& Nicholls 1999). Once multiple time-dependent feedbacks between climate change and socio-economic change are included, then the relative impact of physical climate change, socio-economic change and socio-economic/political responses becomes more difficult to untangle (especially if relatively few model runs can be performed because of resource costs).

- The non-climate SESs are combined with appropriate climate-change scenarios in the integrated assessment. Hence, the regional enterprise scenario was combined with the high-climate-change scenario, because it is a high-growth, high-fossil-fueluse scenario. The global sustainability scenario was
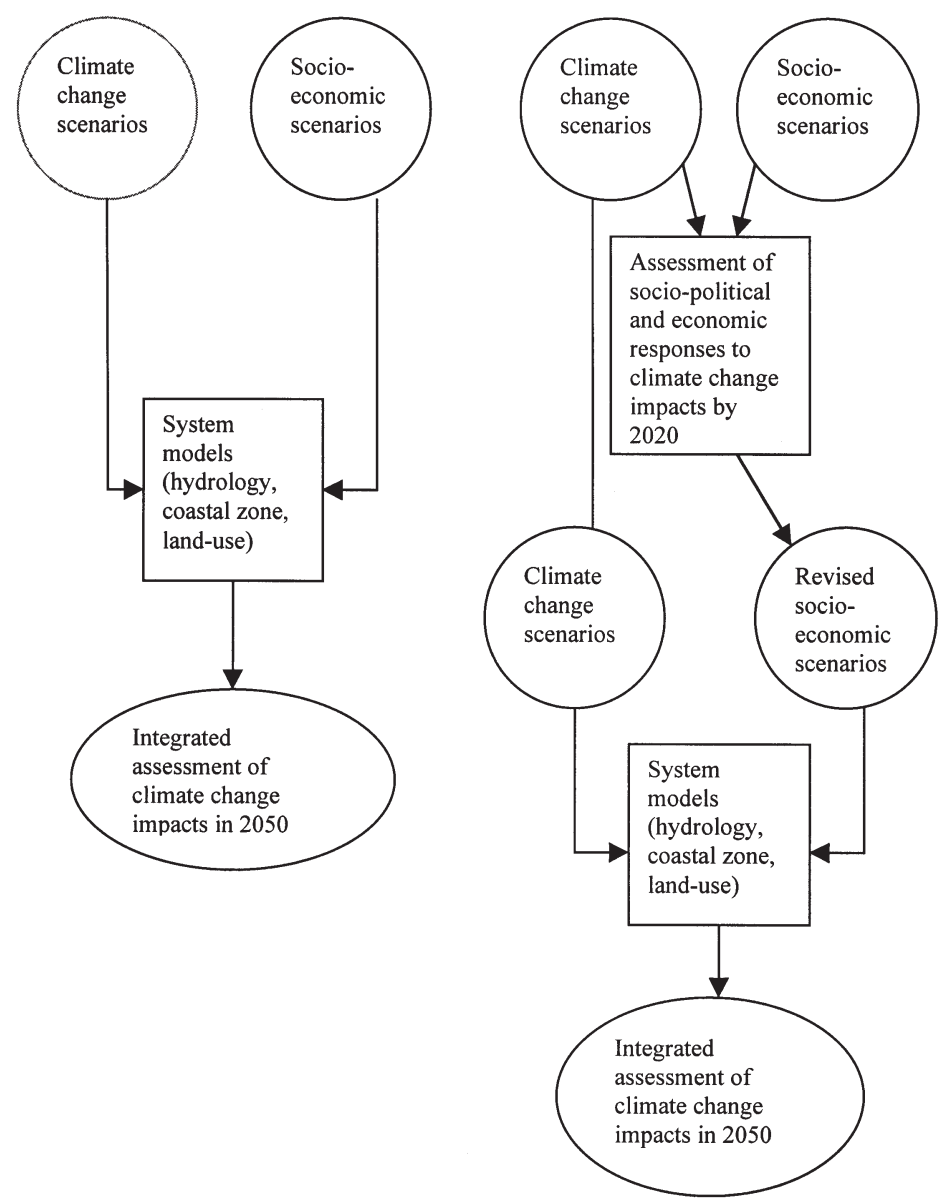

Fig. 2. Independent (left) and co-evolutionary (right) scenario techniques 
combined with the low-climate-change scenario, because it implies a transition to an energy system with a lower carbon intensity. Whilst the matchingup of all SESs and climate-change scenarios is not entirely straightforward (Shackley \& Wood 2001), it becomes less viable if socio-economic responses are included in the SESs, because changes to carbon intensity should be included in addition to adaptation.

For these reasons, use of non-climate SESs is a valuable first stage and is the approach taken here. A subsequent step is the co-evolutionary approach entailing further elaboration of the responses and adaptation to the impacts of climate change within each SES at discrete points into the future, in order to permit the effectiveness of alternative adjustments and planned responses and policies (as agreed by the stakeholders and research team) to be explored. In that sense, the work reported on here (and indeed the integrated assessment of the REGIS project) is far from constituting a comprehensive evaluation for decision-making.

\subsection{Response to criticism}

Before entering into the detail of the paper, we address 2 criticisms which were raised by reviewers of this paper. Firstly, are these SESs really about climate change or are they applicable to any forward-looking developments? The scenario framework could indeed be applied to a wide range of social, economic, political and environmental issues. That is a necessary requirement because of the need to incorporate potentially wide-ranging (non-climatic) change in the analysis of climate-change impacts. Yet a generic framework such as provided by the SRES scenarios of the IPCC (2001) or Berkhout et al. (2001) is only the starting point in producing SESs for an integrated assessment of regional climate change. The latter task requires understanding and knowledge of the models used, their outputs and sensitivities and especially those model inputs which are required from the SESs. The scenarios we report on here are therefore highly customised and the result of an extended interaction with system modellers and climate-change specialists. Reporting on the experience of proceeding from the generic scenario framework to the specific customised scenarios is, we hope, a useful contribution to the climate-research literature.

Secondly, it may be asked why we have included details of the SESs themselves in the paper, rather than focusing solely on the stakeholder experience. The focus of the interactions between ourselves, the stakeholders and the modellers was on the content, structure and rationale of the scenarios themselves-hence they have the role of mediating devices. It is not really possible to understand the process of stakeholder interaction without some knowledge of what the substantive focus of stakeholder interest actually was, namely the scenarios themselves. It is comparable to undertaking research on how different stakeholders respond to policy development, where it would be difficult to analyse such responses without some knowledge of what those policies actually are.

\subsection{Structure of the paper}

Firstly, we provide a qualitative description of the socio-economic scenarios, and summarise the interpretations of them for each region in Tables $1 \& 2$. We then proceed to quantifying 2 of the scenarios for each region, explaining how this has been done. The quantification is only possible when a well-formulated qualitative interpretation has been undertaken. Section 4 focuses upon the experience of working with stakeholders in developing these scenarios. We conclude with some lessons learnt and advice for similar future scenario development activities.

\section{DEVELOPING THE SOCIO-ECONOMIC SCENARIOS: QUALITATIVE CHARACTERISATION}

The SESs embrace complex societal and economic change and use this to derive indicators of plausible future states by the 2050s. They do not emerge directly from current practises per se; rather they abstract particular forces for change, differentiating and extrapolating them. Whilst climate-change scenarios are derived from general circulation models (GCMs) which are constructed according to the interpretation of physical processes and the laws which govern them, and are reasonably constrained by known empirical data sets (Shackley et al. 1998), no comprehensive socio-economic model or equivalent methodology exists by which to generate SESs, and there is little accumulated past experience upon which to build. This is not to deny that there are some sectoral or disciplinary models in the social sciences which are robust in certain contexts and timescales (e.g. demographic, economic, land-use models: see Yohe et al. (2002) for some applications in the climate-change impacts field) but there is nothing which combines the many separate interacting strands which together weave the social fabric: at least not which would gain the agreement of the wider social-science community. There are, as far as we can know, an infinite number of possible socioeconomic futures, and unfortunately there is no 
(uncontested) socio-economic theory which can identify the likely range in which the future scenario will fall (contra climate-change scenarios). Major questions therefore arise as to the degree of credible differentiation we can make between the different SESs, and it is difficult to know whether we have robust scenario constituents (in the sense of working through an intellectually defensible process which produces a relevant variable), or whether we are making educated, but ultimately subjective, guesses. The answer to that question is probably unknowable.

We have used the framework set out in Fig. 1, which has been adapted from Berkhout et al. (2001, 2002; who in turn have adapted the IPCC's SRES framework), by a somewhat different interpretation of the top right-hand and top left-hand quadrants (Shackley \& Wood 2001). There are 2 key differences from Berkhout et al. (2001). Firstly, we have redefined their 'national enterprise' and 'local stewardship' scenarios at the regional scale, i.e. 'regional enterprise' and 'regional stewardship'. This seemed necessary for a regionally focused assessment. Secondly, we have interpreted the top-left hand 'regional enterprise' scenario as a high-growth future, unlike Berkhout et al., who regard it as a lower-growth future. In so doing, we are adopting the more optimistic, desired-for future of the regions which is entertained by many regional stakeholders. It is not the purpose of this paper to discuss the merits or otherwise of the framework outlined in Fig. 1. This has been extensively covered elsewhere, reflecting the widespread use of these scenarios and their close IPCC antecedents (e.g. IPCC 2001, UK Climate Impacts Programme 2001, Berkhout et al. 2001, 2002). Our construction of the SESs drew upon the following:

(1) UKCIP SES report (Berkhout et al. 2001).

(2) Discussions within the REGIS team as a whole (consisting of scientists representing hydrology, climate change, soil science, agricultural resources, coastal systems and biodiversity).

(3) Three regional stakeholder workshops held in 1999, which involved approximately 100 stakeholders from the public, private and voluntary sectors, with a professional interest in the regions' environment and sustainable development. We invited all the main bodies who operate at the regional and sub-regional scales that we felt might have an interest in climate-change impacts and successfully attracted most of the key players with a direct regulatory or policy development role (we estimate about $2 / 3$ of our key target organisations attended), as discussed elsewhere (Shackley \& Deanwood 2002). It was not possible to define a formally representative list of regional stakeholders which should be included in the consultation process, because many individuals and groups operate at a range of scales (from local to national); many of these have a potential interest in climate-change impacts, and there is a high degree of overlap between organisational and professional concern with regional climate-change impacts. The English regions are only about 5 yr old as distinct political entities, and many organisations do not yet have a clear regional presence. Hence, there is no obvious demarcation of a representative body of regional stakeholders. Inevitably, we had to rely upon good will, general interest and government sponsorship of the project in order to attract participants.

(4) The spatial development scenarios developed by the North West Planning Team (NWRA 1999).

(5) The structure plans and regional planning guidance for the North West and East Anglia (GOEE 2000, NWRA 2000). (Regional Planning Guidance sets the broad framework in which more detailed local (structure) plans are articulated.)

(6) The regional economic strategies for the North West and East of England (NWDA 1999, EEDA 1999).

(7) Subsequent discussions with stakeholders from both regions on what scenario runs should be explored within REGIS at a workshop in December 1999, involving approximately 20 stakeholders from public, private and voluntary sectors (e.g. regional water companies, Royal Society for the Protection of Birds, the Environment Agency and English Nature, as well as nationallevel civil servants).

(8) Face-to-face meetings with 1 regional planner in East Anglia and 3 regional planners in the North West in August 2000 and subsequent feedback on the characteristics of the 'planners' scenario'.

The 4 scenarios-regional enterprise, global sustainability, regional stewardship and global marketsare interpreted for the regional scale and described below. In each case, the analysis is organised under 3 themes: economy, society and environment. The speculative nature of the scenarios renders them contentious and inevitably subject to disagreement; however, they are only illustrative and are deliberately intended to demonstrate the potential for divergent futures. We have designed the scenarios such that they are evidently distinct but not entirely different from one another or entirely alien relative to the present day.

A planners' scenario was also developed, based on regional planning documents and discussions with planning officers in the 2 regions. The national meeting of regional stakeholders in 1999 requested that such a planners scenario be formulated, in response to 3 main criticisms of the UKCIP SESs.

- Firstly, that the 4 SESs developed according to Fig. 1 were 'extremes', and that in the view of the meeting 


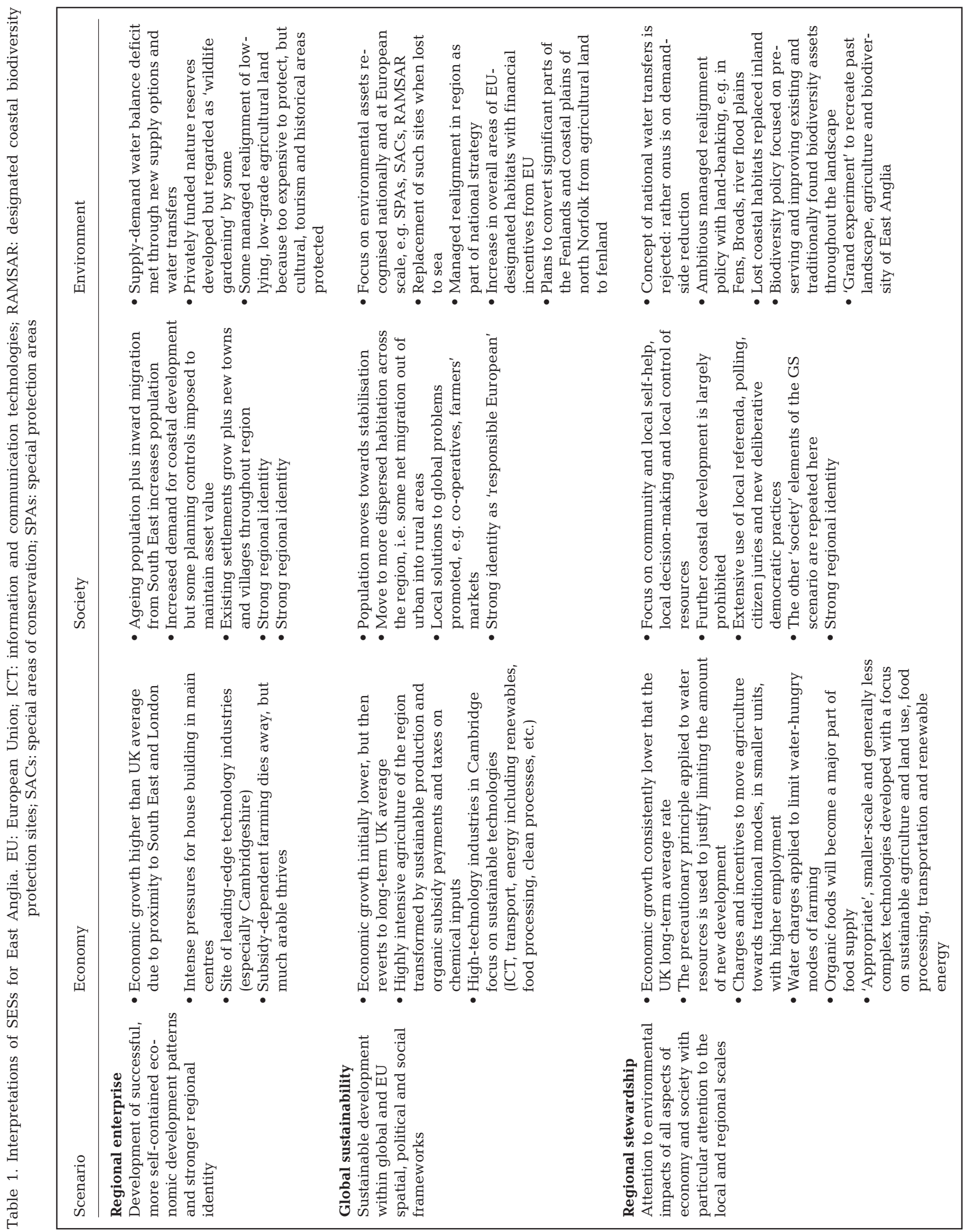




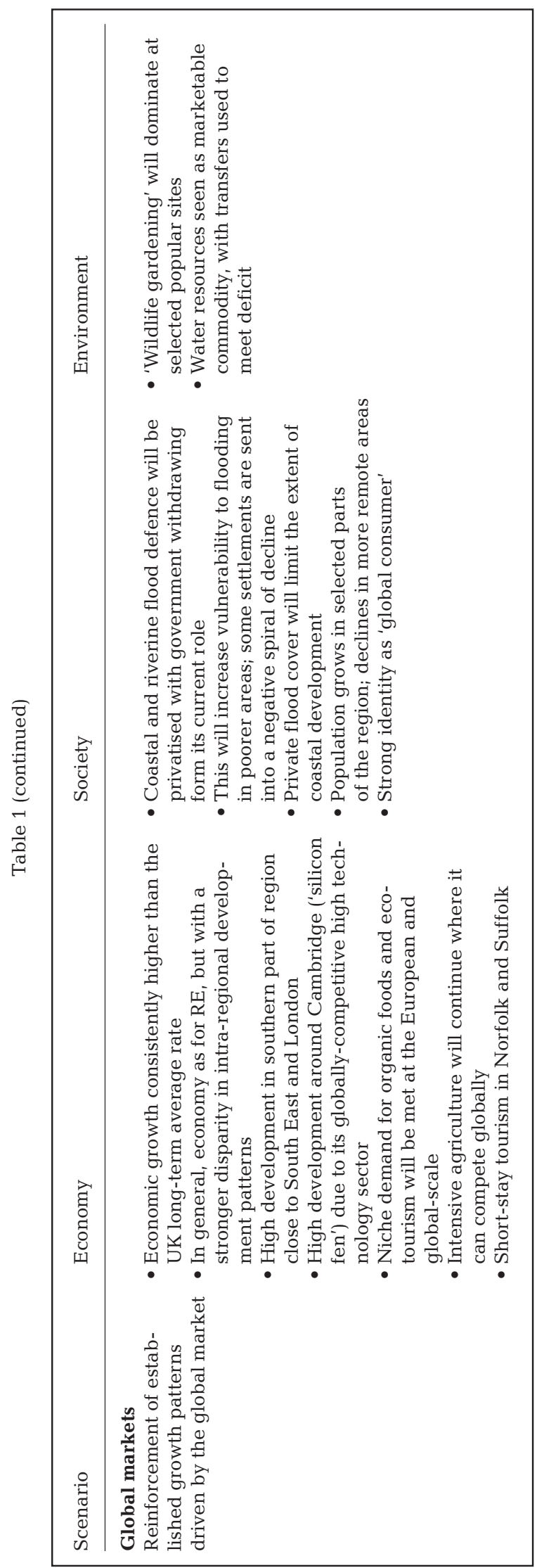

the future was more likely to be a combination of elements of the 4 SESs.

- Secondly, that the 2050 time horizon was too distant to be of direct use in contemporary policy making, and that a nearer-term scenario for 2020 was desirable.

- Thirdly, that the planning process is thinking $15 \mathrm{yr}$ ahead through development of structure plans and regional planning guidance, yet none of the UKCIP SESs related particularly well to the changes envisaged in such 'real world' policy deliberation. The stakeholder group felt that it was important that at least 1 scenario should reflect the state-of-the-art analysis within professional planning.

We felt that the above points were valuable insights and accord with social-science understanding of the co-existence of diverse 'ways of organising' and modes of rationality, rather than the 'ideal types' explored in the UKCIP SES framework (Thompson et al. 1990, Shackley \& Gough unpubl.). Furthermore, engagement with real 'on-the-ground' decision-makers was felt to be facilitated by utilising the longer-term planning trajectory that has been agreed through an analytical and consultative process at the local-to-regional scale. We also elicited from the planners their 'vision' (though not their ideal) of each region by the 2050s. The idea here was to obtain a planning-oriented scenario which would include the inevitability of social complexity and compromise, according to the planners' judgement, yet which could also be compared with the 4 other SESs. We should emphasise that we are not presenting the planners scenario as more or less likely that the other 4 scenarios. It is, rather, a more hybrid scenario which incorporates elements of several of the UKCIP SESs from the perspective of the planning profession.

We now present each of the scenarios in turn. We start with a general description, followed by a more detailed elaboration for both regions in Tables $1 \& 2$. Further details can be found in Shackley \& Wood (2001).

\subsection{Regional enterprise (RE)}

In the RE scenario, the UK regions function as semiautonomous economic units. There is a successful coalescence of economic, social and political interests and patterns of interaction at the regional scale, which reduces the dependency of the regions upon the traditional centres of power and decision-making (both public and private sector) in London and the South East. The highly successful northern and central Italian regions (such as Emilia Romagna) are a good model here (Piore \& Sabel 1984, Putnam 1994, Saxenian 


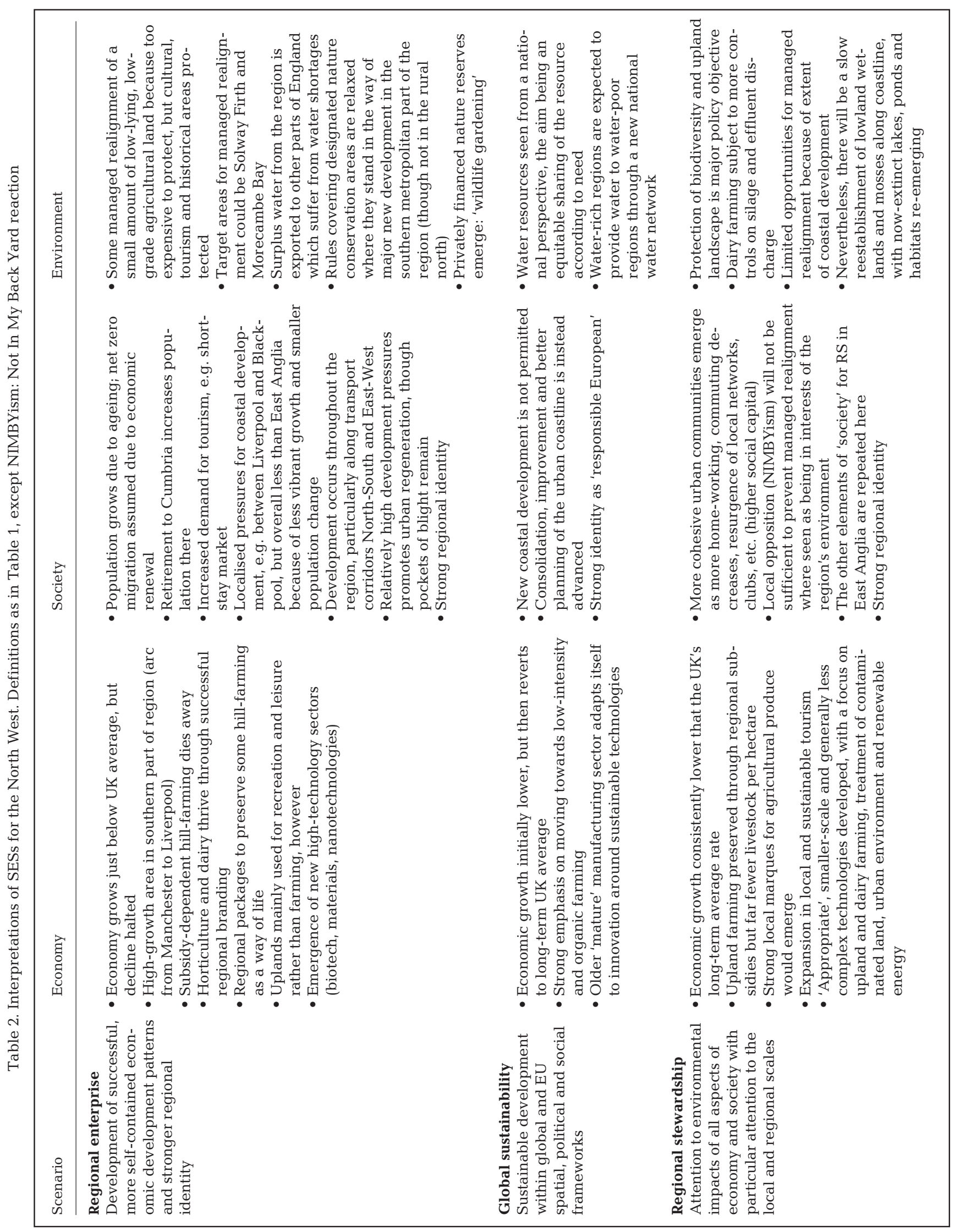




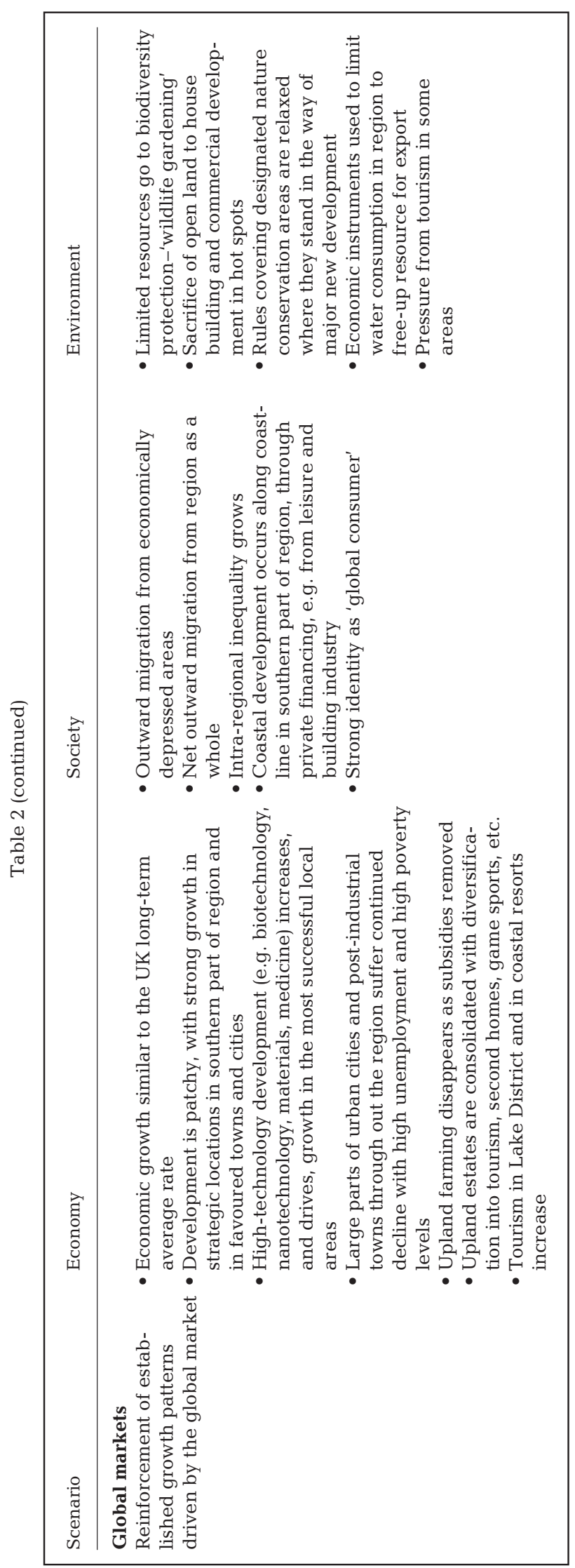

1996). Economic development in those regions appears to have been a function of a strong regionalism, which has cultivated flexible and competitive economic partnerships and supply-chains within the region, especially between smaller companies. This vision of the region is certainly one which is widely shared amongst policy makers at the regional scale, as indicated in regional economic strategies (EEDA 1999, NWDA 1999). Use of this scenario allows the consequences for regional water, biodiversity, the coastal zone and agriculture of the implementation of many policy makers' own desired futures to be explored.

2.1.1. Economy. The regional economy grows at slightly above the long-term average rate. Agriculture will become more exposed to market forces and could decline as a result, although there would be support where this promotes regional cohesiveness. Technology development is promoted within the region, though strong links remain with outside sources of technological innovation.

2.1.2. Society. A high degree of devolution to regional government will facilitate considerably more regional networks, policy and decision-making and political involvement than is currently the case.

2.1.3. Environment. A greater awareness of the role of the environment as a regional economic asset and a fundamental part of quality of life is characteristic.

\subsection{Global sustainability (GS)}

Here the global approaches to achieving sustainable development take precedence over regional responses (cf. the RS scenario below). The World is seen as an interconnected whole, functionally and morally, with a concentration on the wider impacts of individual actions.

2.2.1. Economy. The economy grows at a slightly lower rate than the long-term average. A reformulated EU Agricultural Policy encourages growth of the most suitable crops locally in the context of the European landmass. Development patterns reflect a desire to conserve greenfield resources, and cities become substantially more compact than at present, their character transformed through city greening, new public transportation systems and the establishment of pedestrianoriented enclaves. Nevertheless, some new greenfield settlements are developed where these can demonstrate a high degree of self-containment and the enhancement of the landscape into which they are placed. Environmental externalities will be more comprehensively included in economic costs, at a relatively low level agreed within global trading regimes. Technology $\mathrm{R} \& \mathrm{D}$ will be directed towards sustainable production and consumption and will be accessible globally. 
2.2.2. Society. The degree of popular awareness of global development and sustainability issues is high. Sustainability considerations will lead to conflict over individual choices (such as a desire to find a higher quality of life in the countryside but being restricted by the environmental impacts and associated costs of travel).

2.2.3. Environment. Biodiversity and water resources-and priorities for conservation and improvement-are analysed at the European and global scales. Coastal protection policy is directed towards the most vulnerable regions considered in a national context. There is some restoration of coastal salt marsh and freshwater habitats given that such habitats are key to the survival of internationally important populations of migratory bird species. Tidal barrages for renewable energy generation and storage of freshwater will be evaluated in both regions (e.g. Wash, Mersey, Wyre, Morecambe Bay), though controversy over environmental impacts will delay any firm decision.

\subsection{Regional stewardship: RS}

Here the emphasis is on recognising and conserving regional assets, accepting that this might result in a significantly reduced level of economic growth and even a contraction of the economy. A more all-embracing way of living is accepted which recognises the importance of local community, quality of life and the value of local natural assets.

2.3.1. Economy. The economy grows more slowly than in any other of the scenarios. Environmental externalities are incorporated into economic costs at a relatively high level through a combination of national and regional economic instruments. There are significant support packages for local industries which benefit environmental integrity (such as renewable energy, clean technologies and sustainable agricultural methods). The development of small businesses and cooperatives serving local demand will be encouraged as part of more community-focused ways of living. The (relatively-limited) regional technology R\&D which is directed towards sustainable production and lifestyles will also flourish, and somewhat bring down the costs of, e.g. locally sourced organic foods and biofuels. Extension of global markets into the regions will be limited through imposition of trade tariffs aimed at charging importers the full costs of environmental externalities. This will limit the availability of technologies developed outside of the region, thereby increasing costs and slowing-down the implementation of existing and new technologies (including more sustainable ones).
2.3.2. Society. Policy making will involve extensive public consultation, including surveys, focus groups, citizens panels and juries, and possibly even referenda. Policy comes to reflect as far as possible local and regional concerns, which will tend to turn policy attention 'inwards' to valuing and conserving the regions' stock of assets. This focus on the region is not a denial of global problems and issues, but rather a manifestation of the slogan: 'think globally, act locally'.

2.3.3. Environment. The landscape setting, coastline, agriculture, hydrology and biodiversity resources will be seen as priorities for enhancement to build back the stock of environmental capital which has been eroded since industrialisation. The lower level of economic growth limits the resources available for expensive response measures (such as hard coastal defence) and in any case soft engineering approaches and managed realignment which 'work with nature' are preferred. There is scepticism of 'technological fixes' as the solution to environmental problems and a preference for regionally and community-oriented behavioural and participative responses. Drainage of land will be slowly phased-out as river and coastal defences are realigned, and as the most highly vulnerable settlements in the flood plain are abandoned and their residents relocated. The aim of biodiversity policy will be 'nature in the countryside', rather than wildlife gardening (cf. the RE scenario). Short rotation willow coppice and other biomass for bio-fuels and combustion in local combined heat and power facilities, with further benefits for amenity and rural diversification, will expand, though extensive afforestation will be limited for reasons of ecological diversity and landscape appearance.

\subsection{Global markets (GM)}

A global market orientation is one based on the pursuit of high and sustained growth within a global context.

2.4.1. Economy. The economy grows at slightly above the average rate, but is patchy, with high and low rates within different parts of the regions. Certain areas within the regions will be subject to particularly intense development pressures, with consequences for local land-uses, water resources, the coastline and biodiversity. Meanwhile, other areas will suffer from under-investment and neglect, as global capital flows readily between currently favoured localities. Flood protection will cease to be a standard component of insurance policies, and cover will become much more expensive for those households in flood-risk areas. Technology R\&D will be driven by global market opportunities, with little regard for sustainability. 
2.4.2. Society. Intense competition in a deregulated economy will encourage migration to seek work and disrupt community links to places and people.

2.4.3. Environment. In the high growth areas, there will be significant exploitation of environmental resources to meet the overriding demands of global capital (and with very little internalization of external costs). Strategic economic decisions will override local interests, although there will be recognition of the economic value of some environmental resources for the leisure and tourism industries.

\subsection{Planners' 2020 commitments and 2050's vision}

The scenarios for development by 2020 are based on the projections of Regional Planners for housing development over the next $20 \mathrm{yr}$, and informal discussions with regional planning teams. The projections are based on figures for housing commitments contained in the draft Regional Planning Guidance for East Anglia (GOEE 2000) and for the North West (NWRA 2000) and reflect pressures for development. These commitments are location specific but are not necessarily a guide as to the type of development which will be permitted (in terms of density for example) or the extent of future development beyond the $15 \mathrm{yr}$ time frame of the planning guidance. Whilst we have been able to use some of the numbers for population flows and new household numbers provided in draft Regional Planning Guidance, therefore, we have had to speculate on where precisely such development might take place. This we have done through face-to-face discussions with members of the regional planning teams responsible for production of the Regional Planning Guidance in both East Anglia and the North West. We view the numbers provided not as 'projections' but as an additional scenario based on 'dynamics as usual', as moderated by planning. We have then attempted to create a scenario for the 2050s from the planners' scenario for 2020, largely through a reinforcement of the trends to 2020. Again, this has been achieved through discussions with regional planning officials, including feedback on our first draft scenarios for 2020 and 2050.

2.5.1. East Anglia. The Cambridgeshire sub-region is the centrepiece of development activity up to the 2020s, based on the explosive growth of the knowledge-based economy here. The rapid development of adjacent Peterborough further enhances the vibrancy of this part of the region. New solutions for housing will be well advanced by the end of the 2020s, particularly new settlements surrounding Cambridge. However, the constraints of infrastructure capacity, water resources and health services will begin to bite during this period, and significant investment dilemmas will appear. Rural depopulation in the less accessible east and north east of the region is likely to remain a problem. Nevertheless, the allocation of significant housing growth to Norwich and towns such as Thetford and Dereham reflects the desire to meet latent demand for housing and help stimulate economic growth. The further expansion of the Cambridgeshire sub-region emphasises the importance of nationally and internationally competitive areas, and the role of this part of the region in the European growth arc.

The period to the 2050s is likely to see continued urban expansion, notably in the existing centres of economic activity (Peterborough, Cambridge, Norwich, the A14 road Corridor and along the A11 and A12 road routes from the region into Greater London). Limited scope for 'brownfield' development means that, building on trends evident by the 2020 s, considerable attention will have to be paid to the development of new settlements. The tide of rural depopulation will have been halted by this time, using developments in information and communication technologies (ICT) to establish new patterns of rural working and living. Dilemmas over further road development is likely to be a critical issue by this time, as areas without good communication links slip further behind those which are well connected inter-regionally and internationally.

2.5.2. North West. The pattern of development proposed in the North West to the 2020s is one of modest growth centred on existing settlements. The northsouth axis is the focus for much growth, particularly linking the towns and cities spanning the M6. The integrity of the Green Belt is respected with only relatively minor revisions to its current boundaries. The rationale for higher urban densities along with the reuse of derelict and brownfield land is driving current thinking, with considerable areas of vacant land (notably in East Manchester) awaiting redevelopment. A difficult balance is being sought, however, between the urgency of regeneration and the desire of people (and builders) for specific kinds of property, ideally in greenfield locations. The development of the philosophy and practice of city greening will be central to the realisation of the planners' aspirations of reversing the tide of urban out-migration. Complex commuting patterns will still characterise the next $20 \mathrm{yr}$, reinforced by the success of some 'hot spots' within the region (such as Chester and Warrington) and the availability of cheaper housing immediately outside the region (principally North Wales).

By the 2050s, a halt to out-migration from the region is expected combined with a significant urban renaissance which attracts people back into the urban cores. Some of these could be second homes but the growth of ICT is likely to stimulate even more complex patterns of working and living. Travel patterns are likely to be different, 
based on restrictions, cost and the potential for homeworking. The region will reach for a higher European profile, and the development of stronger trading links both with adjacent regions and across Europe based on significantly increased rail, and possibly air, freight capacity. The structure of industry and agriculture is likely to be significantly different, with substitution of upland agriculture by land stewardship and management for biodiversity, tourism and recreation.

\section{QUANTIFICATION OF THE SOCIO-ECONOMIC SCENARIOs}

The variables which needed to be quantified in the SESs as inputs to sectoral models are outlined in Table 3. Space precludes a detailed analysis of how quantification was progressed for each variable; instead we will focus on the derivation of the scenarios of development for the 2 scenarios which were requested by the integrated assessment modellers: RE and GS. We should stress that the precise numbers are informed guesses which are illustrative of the particular scenario in question; they have been derived by judgement based on literature review and iteration with experts and stakeholders.

\subsection{Spatial variables for urbanisation}

The spatial patterns of urbanisation are illustrated for today, and in more detail for the North West for the RE, GS and planners' scenarios (Fig. 3). A $5 \times 5$ $\mathrm{km}$ grid is used as the basic mapping unit into which values for current urban, forest and protected area (RAMSAR, SAC and SPAs) coverage are apportioned, this being the size of the grid used to map the climate-change scenario variables. These values are then adjusted according to the qualitative thinking behind the RE and GS scenarios for the year 2050. The scenarios were formulated such that the differences are visible both compared to today and for comparison of each scenario. Ordnance Survey maps and discussion with regional experts were used to try to ensure that the changes are credible and physically plausible. Hence extensive development along many parts of the North Norfolk coastline has not been proposed under RE, since there are physical limitations due to the lack of suitable land for building between the salt marshes and the higher ground that rises behind the coastline. Likewise, new settlements have not been put on top of the Pennine Hills, since there would be major logistical obstacles to such development and a lowland development is much more feasible. The scenarios were presented to the national stakeholder workshop (item 7 in Section 2) for discussion and agreement that they should be utilised. As noted above (item 8), the planners' scenarios were also agreed with a representative of the regional planning teams. Such 'agreement' reflected a broad consensus that the scenarios were 'good enough for the job', rather than in most cases a proactive engagement and confirmation (a point to which we will return).

Table 3. Summary of scenario indicators which required quantification. Source: Mark Rounsevell, University of Louvain. NVZ: Nitrate Vulnerable Zone; NSA: Nitrate Sensitive Area; ESA: Environmentally Sensitive Area

\begin{tabular}{|lll|}
\hline Indicator & Spatial resolution & \\
\hline $\begin{array}{l}\text { Spatial indicators } \\
\Delta \text { urban areas (\%) }\end{array}$ & As fine as possible & $\begin{array}{l}\text { To estimate area available for agriculture } \\
\text { and as habitats. Sub-indicators are popu- } \\
\text { lation, number of households, and density } \\
\text { of development }\end{array}$ \\
$\begin{array}{l}\Delta \text { total agricultural area (\%) } \\
\Delta \text { non-agricultural area, e.g. woodland, }\end{array}$ & As fine as possible & To define the limits of the farm model runs \\
amenity (\%) & As fine as possible & To estimate potential habitats \\
$\Delta$ agri-environment areas, e.g. NVZ, NSA, & As fine as possible & To modify the farm model management \\
ESA (\%) & & inputs \\
Non-spatial indicators & & \\
$\Delta$ crop prices (\%) (all major crops) & UK & Input to farm model \\
$\Delta$ crop yields (\%) (all major crops) & UK & Input to farm model \\
$\Delta$ price of chemical inputs (\%) & UK & Input to farm model + water model \\
$\Delta$ land cultivated organically & UK & $\begin{array}{l}\text { Input to farm model } \\
\text { Input to farm model }\end{array}$ \\
$\Delta$ set-aside (\%) & UK & Input to farm model \\
\hline
\end{tabular}




\subsection{Changes in population and number of households}

Under RE there is an expansion of already attractive suburban areas (principally to the south of Manchester in the case of the North West and around Cambridge, Norwich and Peterborough in the case of East Anglia) along with the development of new and expanded towns and villages as satellites to these attractive areas. Economic growth under RE is pursued through capitalising on assets such as Manchester airport in the North West and nodes of high-tech industrial growth in East Anglia. New development is spread out across both regions under RE, unlike the more spatially concentrated growth and decline associated with GM (not shown here). GS presents a much less extreme development pattern with lower
Urbanisation (current)

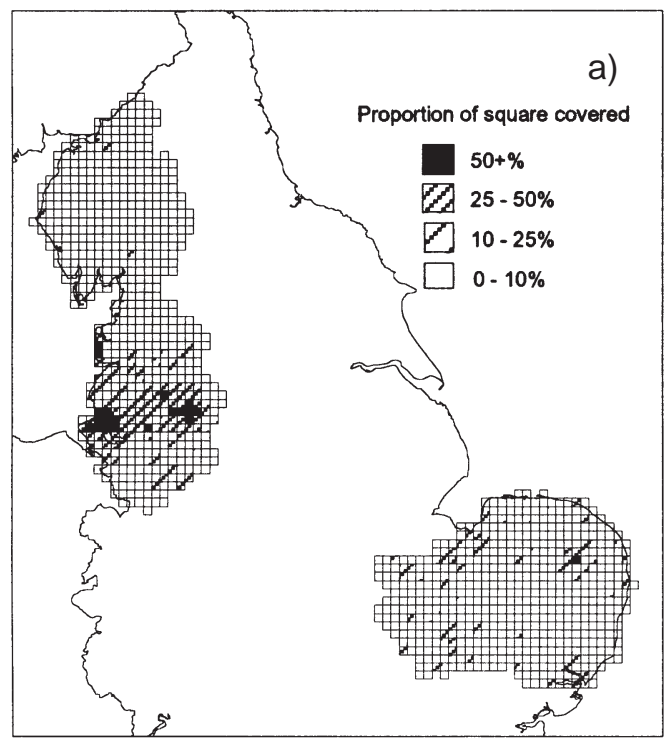

Current Patterns

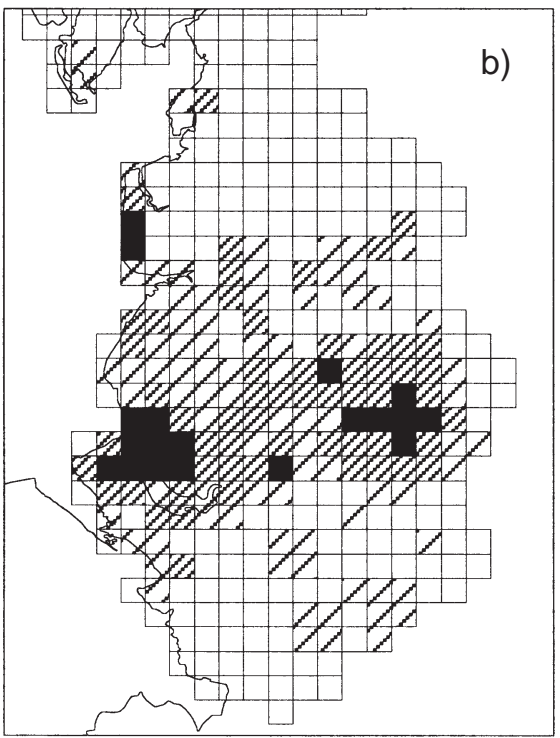

Planners' Projections (2020)

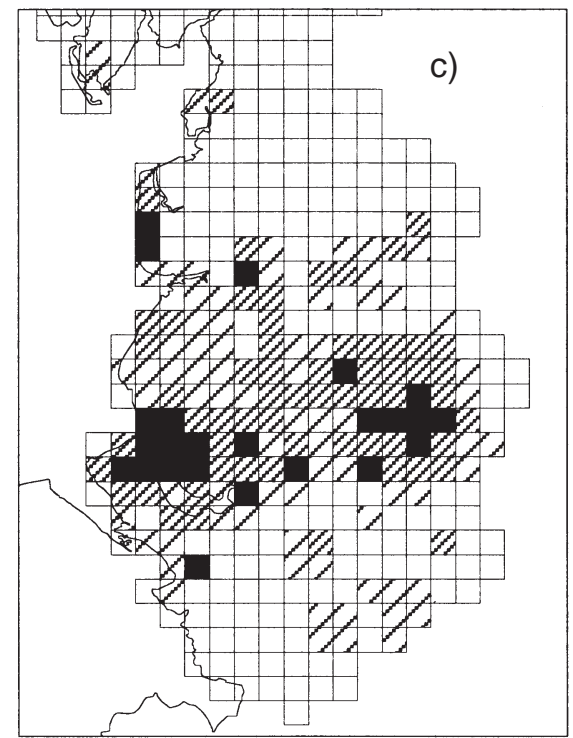

Regional Enterprise

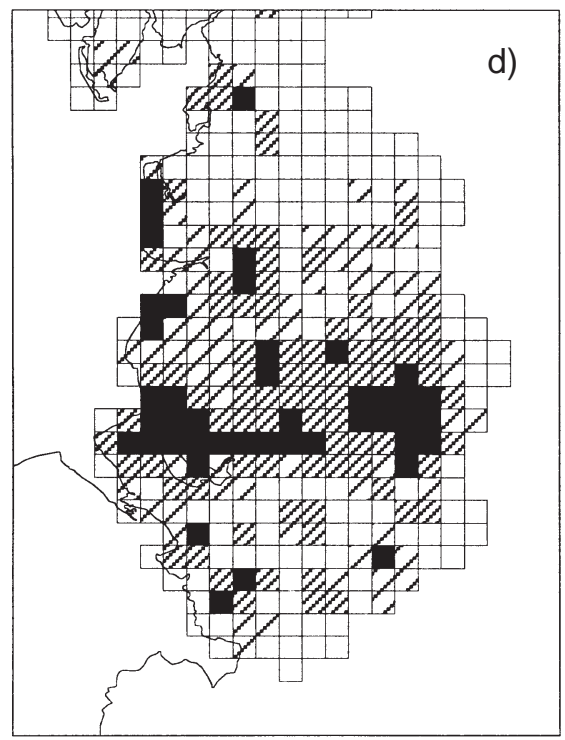

Global Sustainability

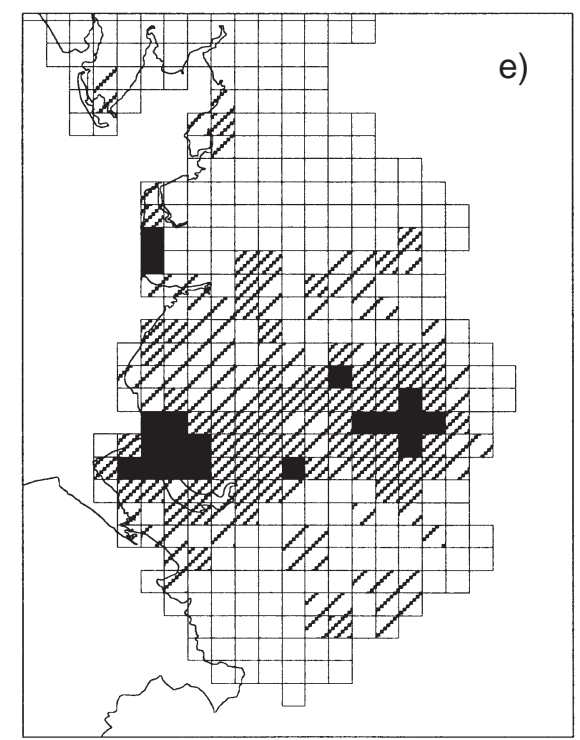

Fig. 3. Current urbanisation patterns (a) in the North West and East Anglia and in more detail for (b) current conditions, (c) the North West planners' 2020, (d) RE and (e) GS scenarios in the North West. Shading: percentage of the grid square occupied by built-up land 
growth, concentrated more around existing population centres. However, relatively limited development of freestanding settlements which help to take pressure away from suburban growth is still a feature of scenarios for both the North West and (more so) East Anglia under GS. This is consistent with our interpretation of GS as both requiring, and more accepting of, development outside of existing built-up areas than the RS scenario, provided that nationally significant assets are not threatened. The population and household numbers for RE and GS are shown in Table 4.

The population numbers were obtained for GS by applying the notion of stabilization at today's levels (which is consistent with long-term stabilisation of the global population having allowed for current demographic trends). For RE, we assumed that economic growth creates a net influx of people into the North West and East Anglia as the need for new employees grows, and as more people choose to retire in the region. The percentage increase in population in the North West is smaller than for East Anglia, however, because of: (1) a lower economic growth rate in the former than in the latter; and (2) the existing population in the former is likely to be able to provide sufficient future workers for the North West region (due to an already high unemployment rate and the occurrence of declining sectors which will over time release part of the workforce for retraining).

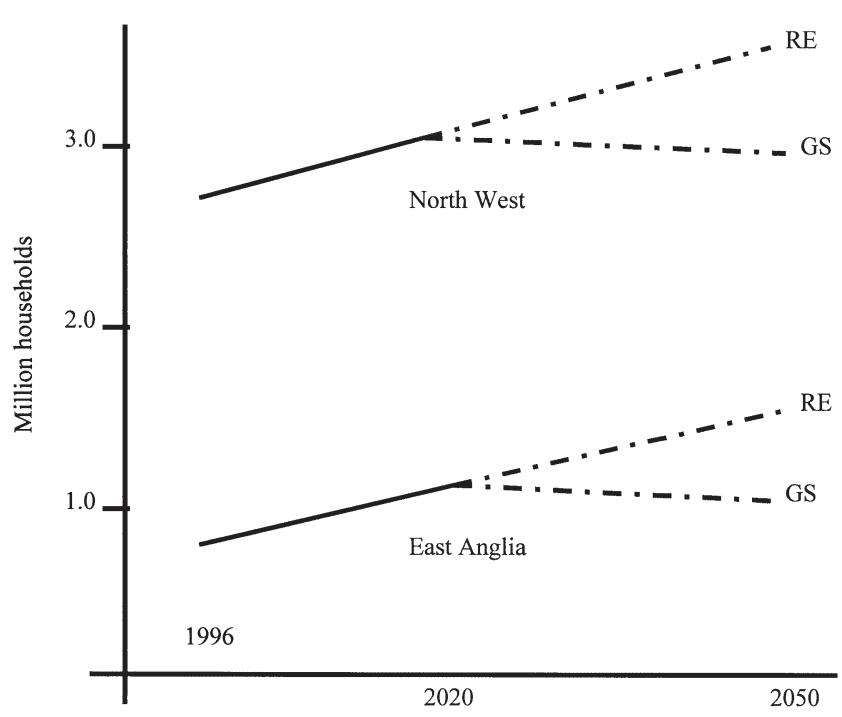

Fig. 4. Planners' projections of household growth in both regions to 2020 (solid line) and scenario-based projections to 2050
The current trend in household numbers was extrapolated forward to 2050, using the government's own data and projections up to 2020. Deviation from this trend was then conducted as illustrated in Fig. 4. In practice, the number of new households was decided by using an iterative method in which the trend towards a lower number of occupants per household was extrapolated and deviation from this trend was executed for the RE and GS scenario. Under GS, there is a reasonably strong focus on community and family, and the average number of persons per household consequently stabilises at current values (2.4 persons household ${ }^{-1}$ ). (We actually increased the number of persons per household under RS, reflecting an even stronger focus on community than under GS). Under $\mathrm{RE}$ there is a strong acceleration of the current trend towards single-occupancy with an average of 1.5 persons household ${ }^{-1}$. This is a consequence of greater affluence and more individually oriented lifestyles.

Dividing the population by the number of persons per household for each scenario and region provides us with the number of households. We have checked that the number of new proposed dwellings is consistent with the spatial area developed under each scenario in the $5 \times 5 \mathrm{~km}$ grid squares. In order to do this, we have had to make an assumption about the density at which development occurs. We have assumed that under RE the density of development (number of households per hectare) is lower than under GS, since RE implies higher levels of affluence and stronger market values. In such a scenario, people are more likely to choose to live in larger plots, with larger houses and gardens than under GS, where the need for more dense habitation will be accepted on environmental and socio-economic cost grounds. The assumptions we have made about density of development are as follows:

- That there will be a mix of development densities in both RE and GS within the current development density range of 15 to 50 dwellings hectare ${ }^{-1}$. 
- For RE, it is assumed that there will be greater development of suburban and outlying areas, which will be of a lower density ( 25 dwellings hectare ${ }^{-1}$ ).

- For GS, conversely, it is assumed that there will be higher rates of development within the current envelope of the built-up area, with attendant higher densities (35 dwellings hectare ${ }^{-1}$ ).

\subsection{Biodiversity}

The patterns of change in biodiversity designations are rather more complex, given that those areas of par- ticular merit are already likely to have attracted protected status, often being the remnants of once far more extensive habitats (Fig. 5). Re-creation of such areas is likely to be extremely difficult for ecological and landscape reasons, but there are notable opportunities in respect of coastal wetland habitats and the East Anglian Fens. Under GS it is envisaged that extensive areas of farmland would be deliberately let back to the influence of tidal flooding as part of habitat re-creation; under RE this would happen to a much lesser extent, and where it does it would be for reasons such as the development of eco-tourism enterprises (see Fig. 5).

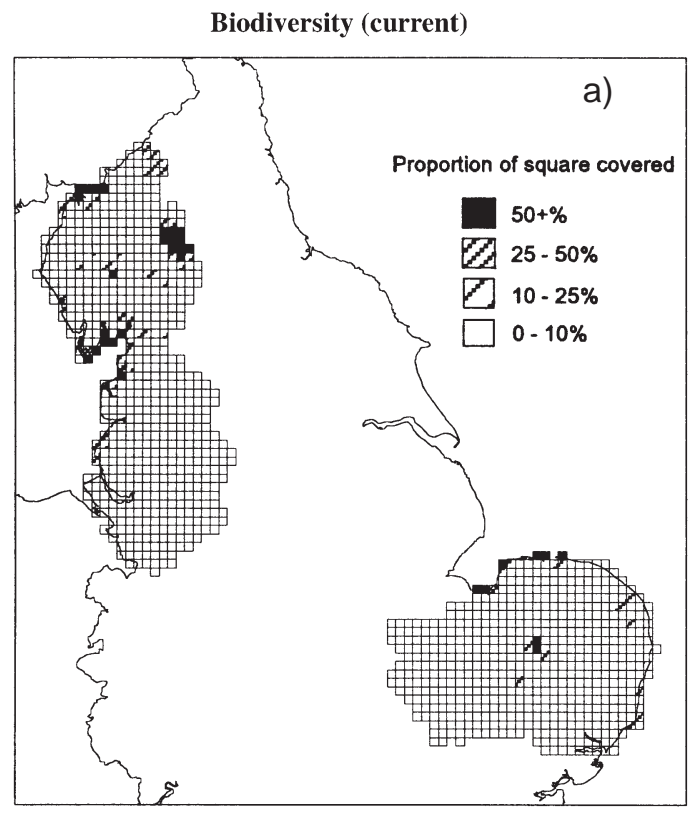

Regional Enterprise

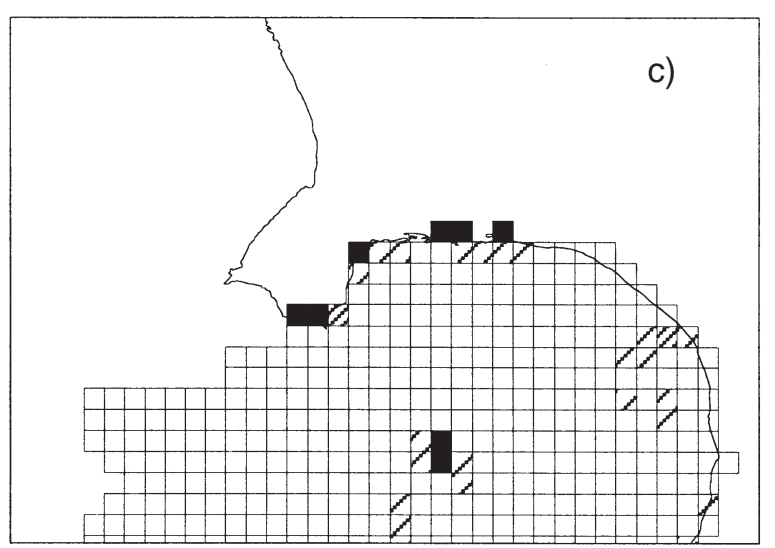

Global Sustainability

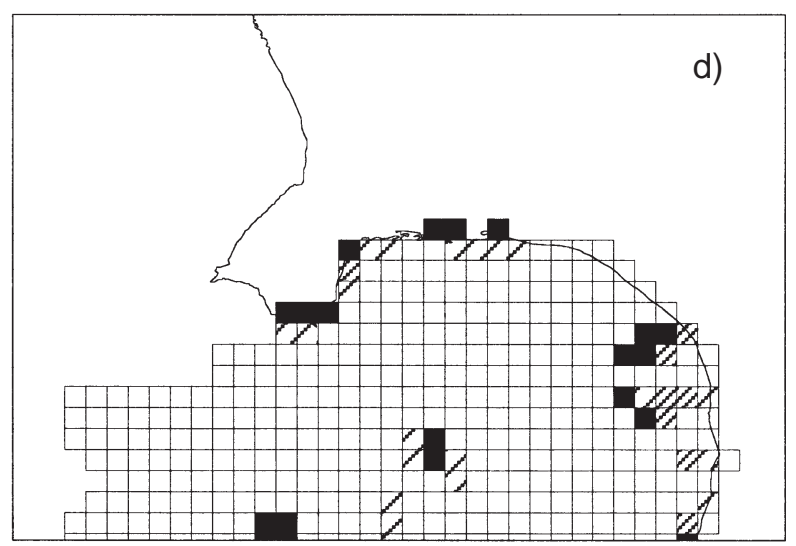

Fig. 5. Current biodiversity patterns (a) in the North West and East Anglia and in more detail for East Anglia (b) under current conditions and using (c) RE and (d) GS scenarios. Shading: percentage of the grid square occupied by a designated biodiversity site 


\subsection{Coastal development}

New coastal development under RE will be protected by the construction of new defences built to 1990 standards and will not include the present yearly increment to account for climate-change induced sealevel rise. An increase of $2 \mathrm{~mm} \mathrm{yr}^{-1}$ is permitted for new East Anglian defences (as at present) to take account of land subsidence. It is assumed that existing defences will be replaced if necessary by 2050 and maintained at the standard specified in 1990. There did not seem to be any good reason why the level of flood defence would increase or decrease from present under RE. The $5 \times 5 \mathrm{~km}$ grid squares were too coarse to allow for the influence of private-sector led coastal flood defences (as in the qualitative scenario) to be included in the mapped scenario. Under GS, there is a full implementation of the official Shoreline Management Plans (SMPs) for both regions by 2050, reflecting the adoption of modest thinking on sustainable coastlines (as opposed to the more radical approach anticipated under RS). The SMPs imply selected managed retreat and the levels of protection can be quantified spatially from the documentation of the Plans.

\subsection{Non-spatial scenario variables for agriculture}

The general change in crop and produce prices, yields and costs of chemical inputs are as shown in Table 5 (the actual percentage changes from the current baseline for each crop and form of produce for 2020 and 2050 can be found in the full REGIS report at www.ukcip.org.uk/integ_assess/integ_assess.html). As a general principle, a range of values greater and less than current values have been selected, since allowing for change in both directions is (1) quite credible given future potential technical, socio-economic and policy changes and (2) more robust than assuming that future change is unidirectional.

Under GM and RE, crop prices will decrease, the rationale being that a fully functioning (global) market should reduce inefficiencies in production, increase yields and hence force down prices. Paul Waggoner has used a simple model to suggest that crop prices will fall by $0.5 \% \mathrm{yr}^{-1}$ to 2050 which apparently matches the 1900-1984 fall of world prices for main agricultural products (Waggoner 2000, pers. comm.). Under, RS we see an increase in prices as environmental policies kick-in (reduction in chemical inputs etc.) and as a more regional focus reduces access to global state-ofthe-art technology and practices. Subsidy levels are reduced but are not removed altogether in order to support regional producers. The RS prices are higher than for GS, because the latter takes a wider-scale perspective, which results in fewer and less onerous environmental policies in East Anglia and the North West relative to those in place in RS.

As for crop yields, innovation is high under GM as global biotechnology develops quickly, leading to the highest increases in yield (which helps to explain lower prices despite increases in demand from an expanding, more affluent population). Under RE there is also promotion of innovation, though less access to the best global technologies and practices, leading to somewhat smaller yield increases than under GM. GS sees a modest increase in yields to 2020 s, as R\&D already underway bears fruit-though not so much as in GM because much of that R\&D underway over the next decade or so is regarded as promoting lesssustainable forms of agriculture. However, by 2050s, the pace of innovation has speeded up, as the R\&D funded globally comes to reflect the promotion of sustainable development-crop yields correspondingly go up. This could include 'sustainable' uses of biotechnology and GMO (genetically modified organisms), for example, and major innovation in organic cultivation. Finally, under RS, yields remain pretty much what they are today as a result of stricter environmental policies and limited resources available for R\&D on sustainable agriculture. Sustainability under RS is defined in terms of lower yields in any case, so none of this is regarded as a problem but as part of the solution.

Yields were calculated for each crop individually. This is necessary because agricultural land use as determined by the IMPEL land-use model (Rounsevell 1999) employed is very sensitive to yield changes if there are differences between crops. There may be very little land-use change observed under climatechange scenarios if the same percentage yield change is imposed on all crops because the model works by comparing the gross margins between crops. The

Table 5. General approach towards quantification of agricultural variables

\begin{tabular}{|c|c|c|c|c|}
\hline Change variable & GM & $\mathrm{RE}$ & GS & $\mathrm{RS}$ \\
\hline Crop prices relative to current baseline & Lower & Slightly lower & Slightly higher & Higher \\
\hline Crop yields relative to current baseline & Much higher & Higher & Slightly higher & Slightly lowe \\
\hline Costs of chemical inputs relative to current baseline & Slightly lower & Slighly higher & Higher & Much higher \\
\hline
\end{tabular}


method for obtaining changes in yields (following advice from Paul Waggoner 2000, pers. comm.) was as follows:

- Establish the trend in crop yield using the longest data set of yield for a given crop in the UK (over $100 \mathrm{yr}$ for wheat, $30 \mathrm{yr}$ for most other crops) (using Nix 1970-1999).

- Extrapolate the best-fit line into the future.

- Deviate from the best-fit line according to the thinking above.

Some examples of the historic change in yields and the deviations from the best-fit line are illustrated in Figs. $6 \& 7$. The size of the changes in yield are slightly conservative relative to the judgement of a number of experts (e.g. Dyson 1996, Waggoner 1997). More pessimistic viewpoints, e.g. those of Brown \& Kane (1994), who suggest that yields may only increase by approximately $10 \%$ over the next $50 \mathrm{yr}$, are reflected in RS.

Under GM, competition, consolidation and economies of scale push down the prices of fertilisers, nitrogen and phosphorus inputs. Under RE prices rise because of the lack of global economies of production and/or the need to purchase these specialised products from other regions which can charge a premium. Prices go up even more under GS and RS as a result of environmental taxation of pesticides and other chemical inputs. The prices are relatively higher for RS than for GS because global production (and associated economies of scale) can still occur in the latter; also a larger number of local habitats are more protected under RS than under GS.

\section{DISCUSSION}

We now return to the 2 questions we put forward in the introduction, tackling them in reverse order.

- How can we quantify SESs which are derived from a qualitative development of different storylines and what problems are implied by a quantification?

With a carefully articulated qualitative interpretation of the scenarios, it was possible to proceed to a plausible and reasonably internally consistent quantification for some, if not all, variables required in the integrated assessment. This task was facilitated by having 4 contrasting scenarios to consider, which allowed characterisation and subsequent quantification by a comparative approach. There was some reluctance amongst the stakeholder sample to proceed with quantification of the qualitative scenarios. This related to the highly judgemental and potentially arbitrary character of quantification, as illuminated above for levels of new development and biodiversity. Each of the individual qualitative scenarios can entertain a fairly wide range of development patterns because of the latitude for dif-

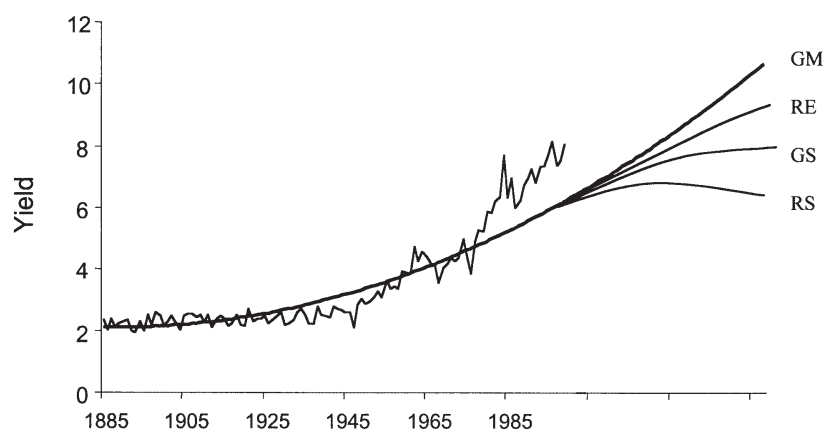

Fig. 6. Historical trend in wheat yields in the UK and scenarios projections (tonnes ha ${ }^{-1}$ ) 1885-1999. Source of trend data: MAFF (www.maff.gov.uk/esg/datasets/datasets.htm)

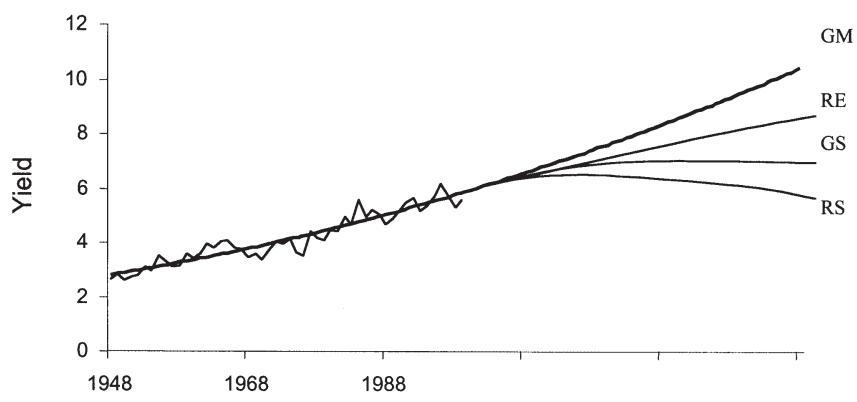

Fig. 7. Historical trend in barley yields in the UK and scenarios projections (tonnes ha ${ }^{-1}$ ) 1948-1999. Source of trend data: MAFF (www.maff.gov.uk/esg/datasets/datasets.htm)

ferent interpretations of what each scenario implies. However, when a particular quantified development trajectory is selected, as above, the precise interpretation of the scenario is further narrowed down. Quantification is also in danger of implying some greater degree of realism and accuracy to stakeholders than can possibly exist, i.e. if it is (incorrectly) perceived as being the output of some theoretically derived and empirically confirmed model, rather than the product of informed guesses, iteration and consultation. It is for reasons such as these that many stakeholders and policy makers who surveyed the scenarios before they were used accepted that quantified scenario descriptions were necessary for the integrated assessment but did not appear to be entirely content with the precise details of the scenarios.

A third problem arises where process-based models require scenario inputs to which they are highly sensitive. These inputs may sometimes be interactive, as is the case with crop yield and price, but the scenario approach does not provide a method for ensuring consistency between these variables. Quantified scenarios are in danger of driving a sophisticated model, which requires precise and internally consistent inputs, with crude and inconsistent values. This problem arose with 
the IMPEL model (Rounsevell 1999), which does not include a feedback between crop yield and price. We therefore had to 'improvise' a feedback within each scenario by calculating the gross margins for scenario combinations of yield and price for each crop, and then checking that the value was within the range of historical variability of the gross margin for that crop in that region (using Nix [1970-1999], University of Manchester Farm Business Unit [1986-1998] and Murphy [1998]). If the change in the gross margins is outside of the envelope provided by the historical data set, then the crop prices were adjusted to bring the gross margins back within the historical range. (Note that this does not limit the effects of climate change upon the gross margins in the integrated assessment.) This is a very crude approximation of a complex economic feedback and implicitly makes questionable assumptions, e.g. about the effects of climate change in other parts of the world upon crop yields and prices. In such cases, it may be more appropriate to replace scenario inputs with model-based inputs (where such models are available) which generate the values of the variables by a (more or less adequate) representation of a process (e.g. Parry et al. 1998, Parry \& Livermore 1999, Strzepek et al. 2001, Yohe et al. 2002). This assumes, however, that such numerical models can represent complex socio-economic processes in the long term. Expert opinion is sharply contrasting on the long-term performance of socio-economic models (Ascher 1981, IAPA 1998, Rayner \& Malone 1998).

- How can stakeholder communities be included in the scenario-building process in a way that encourages maximal engagement of the stakeholders with the outputs of research and analysis?

Our experience suggests that direct stakeholder involvement in scenario construction is an important mechanism for engagement with research. Some care has to be taken in identifying who is the stakeholder client, since some regional stakeholders are more locally oriented and others more nationally oriented. A representative of upland sheep farmers in Cumbria (say) is likely to have a very different take on scenario development than a regional Environment Agency official. Our SES development was informed more by the regionally to nationally oriented stakeholders, who were interested in a cross-sectoral regional assessment, than by the more local and sectorally based concerns. A more bottom-up method of scenario construction, in which the axes of change are themselves elicited through on-the-ground stakeholder dialogue, is likely to be most effective when more local and more sectorally oriented analyses are required.

Most of our stakeholder sample were not familiar with scenario planning approaches, but after an initial period of discussion, most of them accepted the legitimacy of the approach (receiving reassurance from the use of similar scenario approaches by the UK government, the water industry, the IPCC and major businesses such as Royal Dutch Petroleum/Shell). The potential of scenarios was most evident at a rather general level of 'opening minds' and allowing individuals in various organisations to engage in a widerranging analysis and debate than is conventionally achieved within policy. More specifically, scenarios operated as effective 'mediating' devices or 'boundary objects' (Star \& Griesemer 1989) between intellectual debate and policy deliberations, especially where multiple stakeholders with divergent perspectives are engaged. This is because scenarios were able to accommodate the politico-institutional pressure for constraining uncertainty within limits and the epistemological recognition of uncertainty. The diverse policy actors we worked with were prepared to compromise to some extent on the detail of their preferred future option by agreeing to the use of the SESs in the assessment. We speculate that this was because they wished to contribute to, and have influence on, the project as a whole. Hence, whilst each policy actor might prefer to draw up their own future scenario, they may agree to consideration of a smallish number of sufficiently distinct scenarios as the price for moving policy beyond traditional predict and forecasting methods and having more influence in policy development.

When it comes to more detailed and specific policy deliberation and formulation, the problems of uncertainty and complexity are not avoided by using scenarios; they are instead highlighted by the wide range of values and outcomes illustrated. Decisionmakers frequently have to take some decision at some point in time, and the pressure to limit uncertainty becomes pronounced at these decision nodes (Schon 1982, Ezrahi 1990, Jasanoff 1990). (Where decision-makers wish to put off a decision on how to respond to climate change, then the uncertainty of scenarios may be emphasised, and this has been witnessed in the way that water companies have used climate-change scenarios [Shackley et al. 2001].) The perceived need for greater certainty may help explain the pressure for a 'dynamics as usual' scenario (our 'planners' scenario') to be reintroduced into the scenario mix that we initially presented to the stakeholders, i.e. this scenario was perhaps perceived by a number of stakeholders as being 'more credible' than the other 4 , at least up to 2020 . One of our stakeholders also proposed taking the 2 scenario cases we examined, which constituted a 'worse' and a 'better' case, adding up the outcomes for specific variables of interest and dividing by 2 , the assumption being that the average would be a more realistic 
indication of what will actually happen! This is another strategy by which to attempt to reintroduce greater certainty within the scenarios framework. These manoeuvres may be criticised from a 'purist' notion of scenarios and their application, which maintains that 'dynamics as usual' ceases to be meaningful in the medium to long term. Yet, such criticism fails in our view to appreciate the need to accommodate the needs of stakeholders and policy-makers for at least 1 shorter-term scenario, which incorporates significant elements of already planned-for social and economic change. In addition, provision of 'idealtype' scenarios, as provided for by the UKCIP SES framework, does not allow for an aggregated or combined scenario incorporating aspects of those different ideal types, e.g. elements of global markets combined with elements of regional development, global and regional sustainability. The request for more aggregate scenarios is not only theoretically robust (Shackley \& Gough unpubl.), but also more likely to engage practitioners who deal with contradictory rationalities in their everyday work. The rather single-minded futures envisaged in the UKCIP SESs are, arguably, insufficiently flexible to permit their use as 'boundary objects'. Quantification of aggregate scenarios would be more difficult, however, since the clear unidirectional change indicated by an idealtype would be sullied. Nor do aggregate scenarios significantly limit the challenge of decision-making under uncertainty, since they should still represent a wide range of future potential changes.

The capacity of stakeholders to contribute to the development, characterisation and use of scenarios depends upon their own past experience of using scenarios and their back-up resources (time and personnel). To move beyond the fairly straightforward approach to stakeholder engagement adopted here, whereby a smallish number of story lines are used to construct reasonably accessible and transparent scenarios which are presented to, and commented upon by, the stakeholders in a number of stages, would probably require a significantly greater allocation of resources both on the part of the stakeholders and the research team. With more resources, it would be feasible for stakeholders representing an appropriate range of different socio-cultural perspectives to develop scenarios and to take 'ownership' of them (rather than analysts applying a top-down framework). A more vigorous defence (and reluctance to dilute the essence) of different scenarios may well then result. The outcome would no doubt be less tidy than using a single framework, but the dialogue between competing scenarios would perhaps be more influential in helping policy making become more robust to uncertainty and complexity.
Acknowledgements. We acknowledge funding from the UK government (MAFF and DETR, now both DEFRA) and UK Water. Special thanks go to Diana Wilkins, other members of the REGIS steering committee, all other members of the 'REGIS' project team, Paul Waggoner of the Connecticut Agricultural Experiment Station and the stakeholders who consented to be interviewed or who attended workshops, in particular Margaret Gough (SCEALA), Ian Ling (NWRA), Peter Fox and Paul Stainer (Environment Agency). Robert Nicholls (University of Middlesex), Mark Rounsevell (University of Louvain), Eric Audsley and Janet Annetts (Silsoe Research Institute), deserve special thanks.

\section{LITERATURE CITED}

Ascher W (1981) The forecasting potential of complex models. Policy Sci 13:247-267

Berkhout F, Hertin J, Lorenzoni I, Jordan A and 8 others (2001) Presentation of the UKCIP socio-economic scenarios for climate change impact assessment. In: UK Climate Impacts Programme, 2001: Socio-economic scenarios for climate change impact assessment: a guide to their use in the UK Climate Impacts Programme. UK Climate Impacts Programme, Oxford, p 15-65

Berkhout F, Hertin J, Jordan A (2002) Socio-economic futures in climate change impacts assessment: using scenarios as learning machines. Global Environ Change 12:83-95

Brown L, Kane H (1994) Full house: reassessing the Earth's population carrying capacity. Worldwatch Institute, Washington, DC

Collingridge D (1992) The management of scale. Routledge, London

DTI (1999) Environmental futures. Office of Science and Technology, Department of Trade and Industry, London

Dyson T (1996) Food and population. Routledge, London

EEDA (1999) Regional economic development strategy. East of England Development Agency, Cambridge, UK

Ezrahi Y (1990) The descent of Icarus: science and the transformation of contemporary democracy. Harvard University Press, Cambridge, MA

GOEE (2000) Draft regional planning guidance for East Anglia. Government Office for the East of England, Bedford

Hulme M, Jenkins G (1998) Climate change scenarios for the United Kingdom: scientific report. UK Climate Impacts Programme Technical Report No. 1, Climate Research Unit, Norwich

IAPA (1998) Special section on use of models in policy making. Shackley S (ed) Impact Assessment and Project Appraisal 16(2):79-154

IPCC (2001) Climate change 2001: impacts, adaptation and vulnerability. McCarthy J, Canziani O, Leary $\mathrm{N}_{\text {, }}$ Dokken D, White K (eds) Cambridge University Press, Cambridge

Jasanoff S (1990) The fifth branch. Harvard University Press, Cambridge, MA

Klein R, Nicholls R (1999) Assessment of coastal vulnerability to climate change. Ambio 28(2):182-187

Lempert R (2000) Robust strategy for abating climate change. Rand Corp., Santa Monica, CA. Available at www.rand.org/scitech/stpi/Complexity/lempert.pdf

Lorenzoni I, Jordan A, O'Riordan T, Turner R, Hulme M (2000a) A co-evolutionary approach to climate change impact assessment, Part I: Integrating socio-economic and climate change scenarios. Global Environ Change 10: $57-68$ 
Lorenzoni I, Jordan A, O'Riordan T, Turner R, Hulme M (2000b) A co-evolutionary approach to climate change impact assessment, Part II: A scenario-based case-study in East Anglia. Global Environ Change 10:145-155

MAFF (1999) Flood and coastal defence project appraisal guide-economic appraisal, FCDPAG3. Ministry of Agriculture, Fisheries and Food, London

McKenzie-Hedger M, Gawith M, Brown I, Connell R, Downing $\mathrm{T}$ (eds) (2000) Climate change: assessing the impacts-identifying responses - the first three years of the UK Climate Impacts Programme. UKCIP, Oxford

Murphy M (1998) Report on farming in the eastern counties of England 1996/7. Department of Land Economy, University of Cambridge

Nix J (1970-1999) Farm management pocketbook. Wye College, University of London

NWDA (1999) England's North West: a strategy towards 2020. North West Development Agency, Warrington

NWRA (1999) Spatial options for the North West. North West Regional Assembly, Wigan

NWRA (2000) People, places \& prosperity: draft Regional Planning Guidance for the North West. North West Regional Assembly, Wigan

ONS (2001) Regional trends. Office of National Statistics, London

Parry M, Livermore M (1999) A new assessment of the global effects of climate change. Global Environ Change Suppl 9: $1-107$

Parry M, Carson I, Rehman T, Tranter T, Jones P, Mortimer D, Livermore M, Little J (1998) Economic implications of global climate change on agriculture in England and Wales. Research Report, No. 1, Jackson Environment Institute Norwich

Piore M, Sabel C (1984) The second industrial divide: possibilities for prosperity. Basic Books, New York

Putnam H (1996) Making democracy work. Polity Press, Cambridge

Rayner S, Malone E (eds) (1998) Human choice and climate change. Battelle Press, Columbus, $\mathrm{OH}$

Ringland G (1998) Scenario planning: managing for the future. J Wiley \& Sons, Chichester

Rounsevell MDA (ed) (1999) Spatial modelling of the response and adaptation of soils and land-use systems to climate change: an integrated model to predict European land-use (IMPEL), Final Report, Project ENV4CT95-0114, Univ. of Cranfield, Silsoe

Saxenian A (1996) Regional advantage: culture and competition in Silicon Valley and Route 128. Harvard University Press, Cambridge, MA

Schon D (1982) The fear of innovation. In: Barnes B, Edge D (eds) Science in context. Open University Press, Milton Keynes, p 290-302

Shackley S, Deanwood R (2002) Stakeholder perceptions of climate change impacts at the regional scale: implications

Editorial responsibility: Hans von Storch, Geesthacht, Germany for the effectiveness of regional and local responses. J Environ Planning Manage 45(3):381-402

Shackley S, Wood R (2001) Socio-economic scenarios for use in regional climate change impact and response studies (REGIS) in East Anglia and the North West of England. In: UK Climate Impacts Programme. Socio-economic scenarios for climate change impact assessment: a guide to their use in the UK Climate Impacts Programme. UKCIP, Oxford, p 103-119 (available in more detail at www.ukcip.org.uk/integ_assess/integ_assess.html)

Shackley S, Young P, Parkinson S, Wynne B (1998) Uncertainty, complexity and concepts of good science in climate change modelling: are GCMs the best tools? Clim Change 38:155-201

Shackley S, Kersey J, Wilby R, Fleming P (2001) Changing by degrees: the potential impacts of climate change in the East Midlands. Ashgate Publishing, Aldershot

Star S, Griesemer J (1989) Institutional ecology, 'translations' and coherence: amateurs and professionals in Berkeley's Museum of Vertebrate Ecology. Social Stud Sci 19: $387-420$

Strzepek K, Yates D, Yohe G, Tol RJS, Mader N (2001) Constructing 'not-implausible' climate and economic scenarios for Egypt. Integrated Assess 2:139-157

Thompson M, Ellis R, Wildavsky A (1990) Cultural theory. Westview Press, Boulder, CO

UK Climate Impacts Programme (2001) Socio-economic scenarios for climate change impact assessment: a guide to their use in the UK Climate Impacts Programme. UKCIP, Oxford

University of Manchester Farm Business Unit (1986-1998) Review of agriculture in the North West of England. FBU, Manchester

Van der Heijden K (ed) (1996) Scenarios: the art of strategic conversation. J Wiley \& Sons, Chichester

VISIONS (2001) Integrated visions for a sustainable Europe. VISIONS Final Report, Submitted by the International Centre for Integrative Studies to the Research and Development Directorate, European Commission, April 2001, ENV4-CT97-0462. ICIS, Maastricht

Waggoner P (1997) How much land can ten billion people spare for nature? In: Ausubel J, Langford D (eds) Technological trajectories and the human environment. National Academy Press, Washington, DC, p 56-73

Waggoner P (2000) How expensive must food become? Univ. of Stanford, Stanford, CA. Available at www-formal. stanford.edu/jmc/nature/node34.html

Yohe G, Jacobsen M, Gapotchenko T (1999) Spanning 'not implausible' futures to assess relative vulnerability to climate change and climate variability. Global Environmental Change 9:233-249

Yohe G, Strzepek K, Pau T, Yohe C (2002) Economic analysis and adaptive capacity with reference to an Egyptian case study. Wesleyan University, Middletown, CT

Submitted: August 25, 2002; Accepted: January 13, 2002

Proofs received from author(s): April 3, 2003 